a Educación Superior (ES) experimentó grandes cambios y la normativa que reguló al sector se mantuvo con escasas transformaciones. Principalmente se deben mencionar las reacciones de los centros docentes ante la legislación impuesta por la Dictadura en 1981 y la masificación del estudiantado.

Las leyes de 1981 tuvieron por objetivo principal incorporar a la ES a la economía de mercado, con el deseo de introducir competencia entre las entidades participantes, que deberían buscar objetivos rentables en su actuar, lo cual les permitiría una mayor eficiencia en beneficio de la sociedad. Como resultado, se pasó de las ocho entidades estatales y sociales originales a una proliferación de instituciones compuestas por nuevos entes universitarios particulares, Institutos Profesionales (IP) y Centros de Formación Técnicas (CFT).

El sistema creado por la Dictadura se basaba en que las instituciones disponían de libertad para ofrecer sus servicios y los estudiantes eran los compradores, sin considerar las características propias de esta actividad.

La otra transformación importante fue la masificación del estudiantado hasta llegar a más de 1.200.000 matriculados, gracias al nuevo sistema de créditos y becas incorporado. La rápida llegada de esa masa de estudiantes en un breve tiempo ha generado polémicas de todo orden. Entre los aspectos positivos de este logro se debe resaltar no solo la contribución al progreso económico sino la incorporación a la sociedad chilena del "primer miembro de la familia en la universidad", como se ha repetido. Esta es una transformación poderosa y sin retrocesos.

Se reclama que la calidad de los estudios ha decrecido, lo que es natural cuando existen claras diferencias entre los planteles y en la preparación de los docentes. No es lo mismo la calidad entregada por la Universidad de Chile y la Pontificia Universidad Católica comparadas con otras estatales o privadas de reciente formación o CFT. Los procesos rápidos, como la masificación de la ES no tienen ajustes instantáneos sino parsimoniosos.

La aplicación de los supuestos del pensamiento neoliberal, en el sentido que los mercados se ajustan con rapidez y después se obtiene un crecimiento estable, en la práctica no se dan con facilidad y en muchos casos la reacción es lenta, como sucede en este caso; en término ilustrativos, el mercado de la educación superior no es "el mercado de las papas".

También se debe destacar que a pesar de que la normativa de 1981 fue básicamente docente, en el período se incrementó la actividad científica y tecnológica, especialmente con la incorporación de los profesores de jornada completa.

Estos profundos cambios, generados en cerca de 40 años, no fueron acompañados de las correspondientes transformaciones normativas e institucionales, los cuales crearon un ambiente de confusión, conflictos e irregularidades internas, acompañadas de protestas estudiantiles, que hacían cada vez más

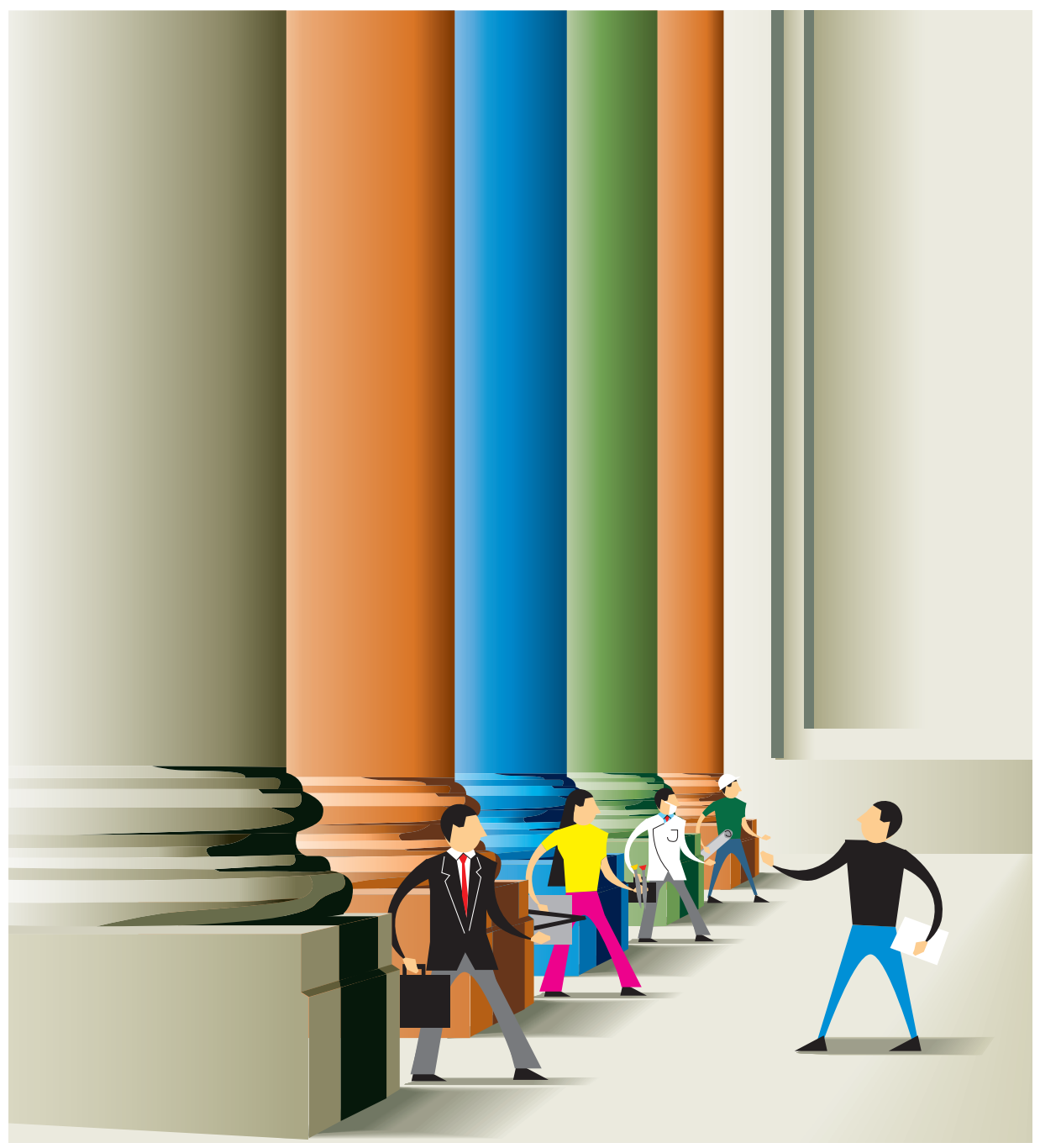

\title{
Avances y conflictos en la
}

EDUCACIÓN SUPERIOR

\section{Los procesos rápidos, como la masificación de la ES no tienen ajustes instantáneos sino parsimoniosos.}

Por Andrés Sanfuentes, Economista, académico FEN+UAH

necesaria una reforma profunda del sector.

La discusión de la reforma se dio en un clima de confrontación entre los actores involucrados, que hizo difícil el cambio legal efectuado en 2017, cuyo resultado muestra algunos avances, pero también temas y conflictos no resueltos.

En esta columna la atención se centrará en algunos temas institucionales, sin profundizar en otros aspectos de carácter más bien financiero, docente, o propiamente de la actividad científica y tecnológi$\mathrm{ca}$, aunque se reconoce la interrelación entre estos asuntos.

Las dificultades que enfrentó la Reforma en su concreción legislativa se generaron por la ausencia de un proyecto de largo plazo que aclarara los objetivos básicos que se buscan para el sector, lo cual centró el análisis en la aspiración de otorgar gratui- dad universal para los estudios, en circunstancias que constituye un medio más que un fin y no existían los recursos humanos y financieros disponibles para lograrla en un período cercano.

La ausencia de un marco general no permitió establecer las prioridades con claridad y de esa manera proponer la institucionalidad adecuada para cumplir los objetivos.

Entre los problemas institucionales se debe partir por tener claridad en la definición de los principales agentes del sistema, en este caso universidades, IP y CFT.

El concepto de universidad que establece la ley, si bien es preciso, se aleja de la realidad actual y futura pues pone como referencia a la institución compleja o completa, en circunstancias que correspondería a una minoría de los planteles actuales, dejando fue- 
ra a aquellos que tienen un carácter básicamente docente, o que realizan pocas actividades de investigación, así como de preparación de sus estudiantes para el doctorado. Si bien puede constituir una aspiración para el futuro, inhibe la formación de entidades dedicadas principalmente a la enseñanza de pregrados de calidad. Algo similar ocurre con los IP y CFT. La diversidad de ofertas puede ser un rasgo favorable si se aspira a desarrollar actividades de buen nivel. Esta condición se da tanto en los centros estatales como privados, así como en los planteles de la capital o de regiones.

Otro aspecto que la nueva legislación no trata adecuadamente es la búsqueda de flexibilidad en la enseñanza, tanto en términos horizontales como verticales. En la actualidad existen dificultades serias para que un alumno pueda emigrar entre diferentes carreras, tanto al interior como entre instituciones, a causa del escaso reconocimiento recíproco de la enseñanza ya aprobada; la carencia de homologación podría ser amainada por un adecuado sistema de acreditación.

La inflexibilidad del sistema también está presente en el tránsito entre los grados académicos, en que cada nivel constituye un compartimiento estanco para moverse entre el bachillerato, la licenciatura, la maestría y el doctorado, de manera de facilitar una secuencia temporal durante diferentes períodos. Esta situación también crea problemas de ineficiencias personales y sociales para el traslado entre los CFT, IP y universidades.

La apertura y cierre de entidades de ES ha sido uno de los problemas que presenta el actual sistema, lo que obliga a cambios profundos. Una vez obtenido el licenciamiento de una nueva institución, no se hace un seguimiento adecuado del cumplimiento del proyecto y la ausencia de controles lleva al fracaso de muchas iniciativas. En 1990 había 302 instituciones, que se redujeron a solo 151 casos en 2018, compuestas por 61 universidades, 43 IP y solo 47 CFT, que tuvieron la mayor reducción en el lapso. La disminución a la mitad de los planteles entre ambas fechas tuvo un significativo costo para la sociedad y los diferentes actores, especialmente los alumnos, tal como lo muestran los casos de las universidades del Mar, Iberoamericana, APSI y Pacífico.

La actual proliferación de sedes y carreras requiere de cambios profundos para mejorar la calidad de la ES. La exagerada duración de algunas especialidades agrava la situación.

Un aspecto institucional que se debe resaltar es que la reforma creó las tan esperadas Subsecretaría y Superintendencia de ES que, si bien tienen un cierto período para su formación, tienen dificultades para un funcionamiento eficaz, por la carencia en el área de suficientes recursos humanos capacitados, tal como ha ocurrido en los últimos lustros, agravados por el estatismo y burocratización que impuso la nueva ley, lo cual significará un complejo proceso de adaptación a las naturales demandas de descentralización y flexibilidad que permitirían mejorar la eficiencia.

También serán tareas complejas resolver el funcionamiento de otras entidades, tales como las transformaciones del Consejo Superior de Educación, el Consejo de Rectores y el nuevo sistema de Acreditación, que debería conservar su autonomía, pero mejorando su actual rigidez.

Junto a su diversidad y diferencias de calidad, las instituciones de educación superior estatales presentan incógnitas por resolver, desde su relación con el Poder Ejecutivo, la designación de su gobierno interno y el sistema de controles administrativos que requerirán la Superintendencia y las atribuciones que ejerce la Contraloría GR, que les impone trabas impropias para una operación eficaz.

Una de las decisiones complejas se encuentra el nuevo Ministerio de Ciencias, Tecnología, Conocimiento e Innovación, cuya primera tarea es realizada principalmente por las universidades, que concentran la actividad científica del país así como la enseñanza de postgrado. En este aspecto se requerirá una estrecha colaboración y coordinación con el Ministerio de Educación, así como una separación precisa de tareas y responsabilidades. Una situación similar se da en las funciones de Innovación, que en el presente corresponden al Ministerio de Economía y la CORFO. Entre las carencias que

\section{"Se reclama que la} calidad de los estudios ha decrecido, lo que es natural cuando existen claras diferencias entre los planteles y en la preparación de los docentes"

se deberán superar es la débil participación y conexión del sector privado con las entidades públicas en el desarrollo científico y tecnológico del país, especialmente por la insuficiencia de los aportes humanos y financieros en uno de los factores claves para alcanzar el desarrollo, como lo muestra la evidencia histórica.

En esta responsabilidad se deberá resolver la dispersión institucional y falta de coordinación entre las instituciones estatales que intentan fomentar diferentes tareas, responsabilidad que tendría que asumir en parte el nuevo Consejo Asesor Presidencial que reemplazará al Consejo Nacional de Innovación. También debería tener un papel importante la nueva Agencia de Investigación, sucesora de CONICYT y otras entidades dedicadas al fomento del desarrollo científico y sus aplicaciones empíricas.

La crítica usual que el país destina escasos re- cursos financieros al desarrollo de la Ciencia y la Tecnología, si bien es válida, no se resolverá si previamente no se discute las orientaciones de largo plazo de una estrategia que establezca las prioridades de la actividad y los organismos ejecutores.

Entre los aspectos más difíciles de resolver se encuentran la compatibilización de las exigencias de la gratuidad y los requisitos que imponen el sistema de acreditación, la fijación de los aranceles y los aumentos en el número de matrículas. Estos elementos han llevado a una incertidumbre de varios planteles: adscribirse 0 no a las normas que impone la gratuidad.

Como la gratuidad solo podrá implementarse en el largo plazo, uno de los aspectos pendientes y no definido es la compatibilidad con el sistema de becas y créditos, que tendrá que subsistir. El Gobierno propuso una modificación al Crédito con Aval del Estado (CAE), que termina por excluir a los bancos de la oferta de crédito, entregando el otorgamiento y la cobranza de los préstamos a una entidad pública (Sistema de Financiamiento Solidario SIFS). En la primera función existe una experiencia positiva en la Comisión Ingresa. Sin embargo, el aspecto crítico se encuentra en la cobranza, en que las experiencias ocurridas han sido desastrosas en manos de entes estatales y universitarios.

Otro tema pendiente son las becas de mantención del estudiante.

En grados de complejidad otro aspecto difícil es la fijación de los aranceles, en especial por la gran variedad de servicios que ofrece la ES, tanto entre diferentes instituciones como por la multiplicidad de carreras y de grados académicos. El aspecto que ha suscitado más controversia corresponde a las diferencias entre la tarifa real que establece la institución educadora en relación con sus costos y el arancel de referencia fijado por la autoridad, tarea que asumirá una Comisión de Expertos.

Un tema no incluido en la normativa actual se refiere al fomento a la regionalización de la ES, en que se estimule la meta de la especialización geográfica de los planteles. En ese sentido, se podrían efectuar aportes basales de largo plazo, concursables, para aquellas entidades que busquen especializarse en actividades propias de la zona y que se agrupen de manera de preparar especialistas de alta productividad.

La legislación dejó ausentes actividades de importancia en la ES, como la vinculación con el medio, la Cultura y las Bellas Artes, las cuales requieren atención.

Las transformaciones en la ES obligan a enfrentar las exigencias del aprendizaje continuo, la necesidad de mentores o tutores para resolver los atrasos en la enseñanza y la adecuación de académicos con capacidad para investigar, pero no para enseñar.

La creación ministerial de un Consejo Asesor de rectores de las entidades de la ES puede jugar un rol importante para destrabar problemas en el futuro cercano. $\mathbf{E}$ 